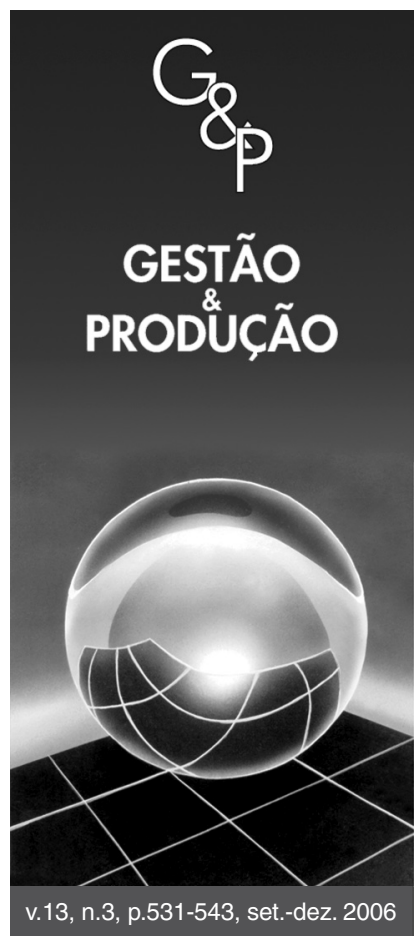

\title{
ESTRUTURA ORGANIZACIONAL PARA A DIFUSÃO DA PRODUÇÃO MAIS LIMPA: UMA CONTRIBUIÇÃO DA METODOLOGIA SEIS SIGMA NA CONSTITUIÇÃO DE REDES INTRA-ORGANIZACIONAIS
}

\author{
Rogério Cerávolo Calia \\ Fábio Müller Guerrini
}

Universidade de São Paulo - USP, Escola de Engenharia de São Carlos - EESC, Avenida Trabalhador Sãocarlense, 400, CEP 13566-590, São Carlos, SP, Brasil, e-mail: rccalia@yahoo.com.br, fabmg@prod.eesc.sc.usp.br

Resumo

Recebido em 29/6/2006

Aceito em 07/12/2006

A “Produção Mais Limpa” é uma metodologia criada para aumentar a sustentabilidade ambiental das manufaturas. Devido a sua importância para o desenvolvimento sustentável, a Produção Mais Limpa foi amplamente promovida pela Organização das Nações Unidas e por diversas redes de organizações visando à difusão desta metodologia. No entanto, após mais de dez anos de atuação, estas redes para a difusão da Produção Mais Limpa têm se confrontado com significativas e recorrentes barreiras organizacionais que limitam seu desempenho. Utilizando-se do referencial teórico de "organizações em rede" no contexto da inovação, este artigo se baseia num aprofundado estudo de caso sobre uma estrutura organizacional em rede dentro de uma empresa multinacional que opera dezenas de manufaturas em diversos países. Esta empresa triplicou o desempenho ambiental em toneladas de poluição prevenidas e multiplicou em oito vezes o número de projetos de Produção Mais Limpa bem sucedidos, após ter implementado uma estrutura organizacional em rede para aumentar sua capacidade de gerenciar projetos para a melhoria de processos. Para explicar os motivos de tal aumento de desempenho ambiental, o artigo utiliza a metodologia de modelagem organizacional Enterprise Knowledge Development (EKD) para descrever as interações entre os objetivos, regras e processos do Programa de Produção Mais Limpa desta corporação, assim como as suas estruturas de relacionamento entre os atores que viabilizaram a integração das competências necessárias para a geração de uma maior capacidade de inovação ambientalmente sustentável nas manufaturas.

Palavras-chave: Produção Mais Limpa, organização em rede, seis sigma, modelagem EKD.

\section{Introdução}

As pesquisas sobre mudanças climáticas e sobre poluição sensibilizaram representantes da sociedade civil e dirigentes governamentais a promoverem a conscientização ambiental. Deste modo, foram criados modelos e metodologias para reduzir a poluição e aumentar a sustentabilidade ambiental nas operações das empresas, tais como a Produção Mais Limpa e a Prevenção da Poluição (Barbieri, 2004). Com o apoio da ONU (Organização das Nações Unidas) e da agência ambiental do governo dos E.U.A. (EPA - Environmental Protection Agency), estes programas contam com evidências documentadas de re- sultados ambientais e econômicos positivos (UNIDO, 2006; REDE BRASILEIRA DE PRODUÇÃO MAIS LIMPA, 2004).

Entretanto, existem barreiras organizacionais que dificultam a difusão destas metodologias de sustentabilidade ambiental nas manufaturas, como (WORLD BANK, 1998; CETESB; PNUMA, 2004; Mello e Nascimento, 2005):

a) a falta de motivação das empresas para implementar a Produção Mais Limpa; 
b) a falta de liderança dos atores locais responsáveis por programas de Produção Mais Limpa;

c) a falta de habilidade nos membros de equipe de implementação de Produção Mais Limpa para superar as complexas barreiras organizacionais e políticas durante a implementação;

d) a falta de suporte interno a membros de equipe;

e) a falta de um padrão ou um sistema formal para definir princípios e processos de implementação; e

f) o fato da Produção Mais Limpa ser vista como uma ferramenta isolada de gestão empresarial, dificultando sua integração no sistema operacional das empresas.

Ante a necessidade de diminuição da poluição e as dificuldades de se difundir práticas ambientalmente sustentáveis de produção, como as teorias organizacionais podem contribuir para a compreensão dos condicionantes da difusão da Produção Mais Limpa?

A recorrência e persistência das citadas barreiras indicam que, atualmente, as redes de difusão da Produção Mais Limpa não têm suficiente controle sobre os condicionantes organizacionais para que as empresas gerem mais projetos de Produção Mais Limpa. Deste modo, o objetivo do artigo é oferecer uma proposta que ajude os responsáveis por programas de Produção Mais Limpa a melhorarem as estruturas e dinâmicas de suas redes organizacionais para aumentar a difusão da Produção Mais Limpa.

Uma possível estratégia teórica para atingir este objetivo é procurar conceitos em áreas de conhecimento com grande experiência acumulada na elaboração de construtos voltados a se compreender os determinantes da estrutura organizacional que capacitam a empresa a conduzir processos de inovação e de mudança. Isso justifica, o enfoque teórico escolhido ser o de redes organizacionais de inovação.

Por outro lado, uma possível estratégia empírica é analisar uma corporação global que controla dezenas de manufaturas, a fim de se compreender como esta empresa conseguiu triplicar o seu desempenho em toneladas de poluição prevenida, por meio de um modelo organizacional que favorece a multiplicação de implementações de projetos inovadores de Produção Mais Limpa.

\subsection{Método de pesquisa}

Para cumprir com o objetivo da pesquisa, serão analisados os componentes e os processos de uma organização em rede com elevado desempenho na difusão da Produção Mais Limpa, por meio de estudo de caso, sob o recorte analítico de organizações em rede.

A metodologia de estudo de caso se presta a pesquisas que procuram respostas a perguntas do tipo "como" e "por que", quando a ênfase se encontra em fenômenos inseridos em algum contexto da vida real (Yin, 2005).
Deste modo, o estudo de caso proporcionará que se investiguem as circunstâncias organizacionais que favorecem a difusão da Produção Mais Limpa, como, por exemplo, as competências dos atores que participam de projetos de Produção Mais Limpa e as estruturas de relacionamento entre os atores.

A empresa analisada, a qual será denominada de "Multinacional Inovadora", tem mais de cem anos de existência desde a sua fundação nos EUA e atua no Brasil há mais de cinqüenta anos. A empresa tem 67 mil funcionários, opera 132 fábricas em 60 países e tem vendas em 200 países. Essa empresa conta com uma extensa linha de produtos e é reconhecida pela sua inovação.

De 1996 a 2000, a empresa analisada preveniu, em média, 10.826 toneladas de poluição por ano mundialmente. Depois de implementar o novo modelo de organização em rede, a empresa triplicou este resultado, ao prevenir, em média, 32.714 toneladas de poluição por ano. Nestes mesmos períodos, o número anual médio de projetos de Produção Mais Limpa aumentou de 39 para 299 projetos, ou seja, aumentou em oito vezes.

O Protocolo de Pesquisa de Estudo de Caso define que será realizada uma pesquisa explanatória voltada à difusão da Produção Mais Limpa (unidade de análise) a fim de se compreender como e por que as redes organizacionais contribuem para a difusão da Produção Mais Limpa. Mais especificamente, o estudo de caso busca respostas iniciais para a questão: "De que modo a organização em rede contribui para a difusão da Produção Mais Limpa no ambiente corporativo?"

O estudo de caso enfoca nas dificuldades de implementar o programa de Produção Mais Limpa na subsidiária da Multinacional Inovadora no Brasil e como as reformulações nas redes organizacionais da empresa proporcionaram uma considerável melhoria no desempenho da difusão da Produção Mais Limpa nas operações brasileiras da empresa a partir de 2001.

Para se obter construtos válidos a partir do estudo de caso, foram utilizadas diversas fontes de dados: Relatórios de projetos, banco de dados do Programa de Produção Mais Limpa, entrevistas semi-estruturadas com líderes de projeto e entrevista não estruturada com o responsável pelo programa de Produção Mais Limpa no Brasil.

Por fim, a validade das conclusões deste estudo de caso se limita apenas a empresas de porte e maturidade organizacional semelhantes aos da Multinacional Inovadora.

Ao se definirem as perguntas específicas do estudo de caso, procurou-se analisar com maior profundidade os motivos que impediram a subsidiária brasileira de reconhecer projetos no Programa de Produção Mais Limpa até 2001 e, de que modo, as estruturas de organização em rede para a condução de projetos Seis Sigma viabilizaram uma expressiva difusão da Produção Mais Limpa nas operações brasileiras da Multinacional Inovadora. 
As conclusões advindas do estudo de caso serão sintetizadas, por meio de uma modelagem organizacional baseada na metodologia Enterprise Knowledge Development - EKD, que é uma metodologia orientada pelos objetivos da organização e é composta por seis modelos (Bubenko, Persson e Stirna, 2001): O Modelo de Objetivos; o Modelo de Regras de Negócio; o Modelo de Processos de Negócio; o Modelo de Atores e Recursos; o Modelo de Conceitos; e o Modelo de Requisitos e Componentes Técnicos. Para os fins desta pesquisa, serão utilizados e explicados apenas os primeiros cinco modelos, pois não faz parte do escopo da pesquisa a elaboração de um sistema computacional.

Segundo o manual "EKD User Guide", o Modelo de Objetivos descreve tanto os objetivos de um empreendimento, como os assuntos relacionados à obtenção destes objetivos, seja ao apoiar os objetivos, ou ao impedi-los (Bubenko, Persson e Stirna, 2001). Deste modo, o Modelo de Objetivos apresenta as razões e motivos que definem os componentes nos demais submodelos. O Modelo de Regras de Negócio serve para definir as regras explicitamente, de modo consistente com os objetivos. Em muitas situações, as regras de negócio podem ser entendidas como um meio de operacionalizar os objetivos, em outras, as regras atuam como fatores que limitam os objetivos.

Já o Modelo de Processos de Negócio retrata como os objetivos são atingidos, pelos processos do empreendimento e o modo pelo qual os processos transformam entradas em saídas, sejam na forma de informações ou na forma de materiais. O Modelo de Atores e Recursos descreve a interação entre os diferentes papéis, departamentos, organizações e recursos necessários para se executar os processos e para se atingir os objetivos, levando em conta as diferentes responsabilidades assumidas pelos atores. Por fim, o Modelo de Conceitos se presta a definir a terminologia adotada nos demais modelos EKD.

\section{Revisão bibliográfica}

A seguir, serão revisados os conceitos sobre a metodologia "Produção Mais Limpa", sobre a "organização em rede" e sobre como uma rede organizacional favorece a inovação. Além disso, também serão levantadas informações secundárias a respeito de algumas das mais importantes redes de difusão de Produção Mais Limpa.

\subsection{A Produção Mais Limpa}

O termo "Produção Mais Limpa" foi definido pelo programa ambiental das Nações Unidas, UNEP - United Nations Environment Programme.

A Produção Mais Limpa é a aplicação contínua de uma estratégia ambiental preventiva aos processos, produtos e serviços, a fim de aumentar a eficiência total e de reduzir riscos aos seres humanos e ao ambiente. A Produção Mais Limpa pode ser aplicada aos processos utilizados em qualquer setor econômico, nos próprios produtos e nos vários serviços oferecidos na sociedade (UNEP, 2006).

Em relação às operações produtivas, o UNEP conceitua:

A Produção Mais Limpa resulta de uma das seguintes ações ou da combinação delas: conservação de matérias-primas, água e energia; eliminação de matérias-primas tóxicas e perigosas e redução da quantidade e toxidade de todas as emissões e perdas na fonte durante o processo produtivo (UNEP, 2006).

A Produção Mais Limpa (Cleaner Production) tem uma abordagem preventiva de gerenciamento ambiental e visa produzir bens e serviços com o mínimo impacto ambiental dentro das limitações econômicas e tecnológicas do presente (UNEP, 2006).

Segundo o SENAI-RS, a Produção Mais Limpa pode ser implementada por diversas ações alternativas, agrupadas em duas categorias: a minimização de materiais e o reuso de materiais. A minimização de materiais prevê a reciclagem interna ou a redução na fonte, com ações de melhoria no produto ou no processo produtivo, na instituição de bons procedimentos de gestão e na substituição de matérias-primas ou modificações tecnológicas. Já o reuso de materiais é feito pela reciclagem externa ou utilização de ciclos biogênicos (SENAI-RS; UNIDO; UNEP, 2003).

\subsection{A organização em rede: cooperação para a inovação}

O conceito de estrutura organizacional passou por várias transições. Num primeiro momento, a estrutura organizacional foi concebida com base nas indústrias em ambientes relativamente estáveis. Mas, com a passagem da economia industrial para uma economia mais baseada em serviços, o ambiente de negócios exigia mudanças mais freqüentes das empresas, estimulando-as a buscar estruturas organizacionais mais inovadoras (Eccles e Nolan, 1993).

A estrutura organizacional se define pelo resultado do processo de distribuição de autoridade, de especificação de atividades e de delineamento de sistemas de comunicação para atingir os objetivos da empresa. Tradicionalmente, as empresas adotavam estruturas organizacionais especializadas, como a Estrutura Funcional, Geográfica, Por Processo, Por Cliente e Por Produto. Com o aumento da turbulência e competitividade no ambiente de negócios, as empresas começaram a adotar estruturas organizacionais inovativas, como a Departamentalização por Centro de Lucros, a Departamentalização por Projetos, 
a Estrutura Matricial, a Estrutura Celular e a Estrutura para Novos Empreendimentos (Vasconcellos e Hemsley, 2003).

Os gerentes de empresas com presença mundial, com frequiência, solucionaram problemas estratégicos por meio de mudanças nas estruturas organizacionais, pois estas mudanças são vistas como ferramentas eficazes para redefinir responsabilidades e relacionamentos, viabilizando que a alta gerência cause impactos imediatos e transmita sinais enfáticos de mudança a todos os níveis administrativos (Bartlett e Ghoshal, 1991).

Neste processo de aprendizagem, as empresas perceberam que não bastam mudanças na estrutura formal da empresa, ou seja, na definição estática de seus papéis, responsabilidades e relacionamentos, uma vez que tais estruturas formais se confrontam com ambientes de negócios bastante dinâmicos. Deste modo, as empresas perceberam ser necessário criar competências e capacidades organizacionais múltiplas, ao se repensar os processos e sistemas decisórios da empresa, os canais de comunicação e as relações interpessoais (Bartlett e Ghoshal, 1991).

De fato, o conceito de estrutura organizacional matricial, por exemplo, explica as relações de poder formais entre os membros de equipe de projetos e os respectivos gerentes funcionais e gerentes de projeto. No entanto, as emergentes teorias de redes intra-organizacionais oferecem construtos mais sutis e precisos para se descrever as estruturas de relacionamento informais aptas para captar e integrar diferentes competências nas equipes de projetos.

As estruturas organizacionais em rede pressupõem a existência de diferentes atores que unem suas respectivas competências complementares, a fim de aumentarem a sua competitividade e melhorarem a entrega de valor ao cliente (Wilkinson e Young, 2002; Lipnack e Stamps, 1994). Por meio de alianças com os atores atualmente em cooperação, também se abre acesso a informações sobre as competências de outros atores para parcerias potenciais no futuro (Gulati e Gargiolo, 1999).

Na perspectiva de uma empresa, para que uma competência possa ser considerada como "competência essencial", é necessário que ofereça reais benefícios ao cliente, seja difícil de imitar e viabilize o acesso a diferentes mercados (Prahalad e Hamel, 1990). Já na perspectiva de um profissional dentro da empresa, as competências representam a inteligência prática e situacional, de acordo com os conhecimentos adquiridos que são transformados com intensidade proporcional à complexidade das situações, nas quais tais competências são utilizadas (Zarifian, 1999).

Para competir na economia global, a estrutura organizacional deve gerar equilíbrio entre uma infra-estrutura global (recursos e práticas de gestão compartilhados) e adaptações ao ambiente específico de cada localidade de atuação da empresa, quanto às preferências dos consumidores locais, às características da força de trabalho e quanto aos regulamentos governamentais. Para isso, Eccles e Nolan recomendam uma arquitetura organizacional "em rede" composta de dois níveis (Eccles e Nolan, 1993):

a) O primeiro nível é de responsabilidade da alta gerência que deve disponibilizar globalmente à empresa a infraestrutura, os ativos, os recursos, as práticas administrativas, as métricas de desempenho e uma clara visão de negócio; e

b) No segundo nível, denominado como o nível do "autoprojeto" ("self-design"), os indivíduos assumem a iniciativa de utilizar a infra-estrutura global para estabelecer os relacionamentos necessários a fim de atingir seus objetivos de negócio.

Deste modo, a arquitetura organizacional em rede consiste de grupos de profissionais internos (e, freqüentemente, integrados a profissionais externos à organização formal) que utilizam as competências, os recursos e as comunicações para atingir um propósito específico (Eccles e Nolan, 1993).

\subsubsection{Redes de inovação}

$\mathrm{Na}$ década de oitenta, estudos procuraram teorizar os fatores estruturais determinantes das atividades inovadoras na empresa (Porter, 1983). Tais pesquisas têm indicado que um fator-chave para o desenvolvimento da capacidade de inovação é a capacidade de uma empresa para estabelecer relacionamentos em uma rede de organizações. Para analisar esse assunto, a OECD procura desenvolver métricas sobre (Stevens, 1997): o fluxo de pessoal técnico; as ligações entre instituições; a formação de pólos industriais; as fontes do comportamento inovador nas empresas; e o monitoramento do fluxo de conhecimento.

A cooperação inter-empresas visa, inclusive, combinar competências, utilizar o know-how de outras empresas, dividir os custos de pesquisas tecnológicas e compartilhar riscos ao realizar experiências em conjunto para explorar novas oportunidades (Amato, 2000).

O conceito de rede de inovação é uma decorrência lógica da complexidade crescente dos produtos e serviços inovadores. Novos produtos integram um número elevado de componentes e funções que, por sua vez, são gerados por uma ampla gama de diferentes competências. Por sua vez, a decorrência lógica da complexidade da inovação em novos produtos e serviços é o fato da inovação requerer competências multidisciplinares integradas. As redes de inovação são justamente uma possível solução organizacional para se operacionalizar a inovação ao integrar um conjunto diverso de competências multidisciplinares (Pyka e Küppers, 2002). 


\subsubsection{Redes de Produção Mais Limpa}

Várias organizações criaram redes nacionais e internacionais para a difusão da Produção Mais Limpa.

Nos Estados Unidos, a agência ambiental criou o "Polution Prevention Resource Exchange" em 1997 para estabelecer uma rede para troca de informações (USEPA, 2006).

No Canadá, foi criado em 1992, o Centro de Prevenção de Poluição, o qual oferece material didático, fórum on-line, grupos de trabalho, treinamentos e certificação (CANADIAN CENTRE FOR POLLUTION PREVENTION, 2006).

Na Grã-Bretanha, foi criado em 1994, o Envirowise que, em dez anos, conseguiu uma economia de US\$1,7 bilhão. Esta agência oferece um balcão on-line, visitas às empresas, guias práticos, estudos de caso e 200 eventos ao ano. (ENVIROWISE, 2006).

$\mathrm{Na}$ Áustria, foi criado em 1991 o ECOPROFIT ("ECOlogical PROject For Integrated Environmental Technology") desenvolvido pelo Departamento de Meio Ambiente da Cidade de Graz, como uma rede de cooperação composta pela parceria entre os setores público e privado em prol do desenvolvimento sustentável. Esta rede obteve em Graz uma redução na fonte de 108 mil MWh de energia, 7 milhões de $\mathrm{m}^{3}$ de água, 6,5 milhões de $\mathrm{m}^{3}$ de efluentes, 4,1 mil toneladas de resíduos perigosos e 10 mil toneladas de resíduos não perigosos. O modelo ECOPROFIT foi patenteado e é replicado em cidades da Europa, Ásia, África e Américas (CLEANER PRODUCTION CENTER AUSTRIA, 2006).

Para os países em desenvolvimento, a ONU criou uma rede em 1989 que integra mais de 100 Centros Nacionais de Produção Mais Limpa em 40 países sob a assistência de institutos de países desenvolvidos. Os Centros realizaram implementações em cerca de 1000 empresas até 2002 (ONU; UNIDO; UNEP, 2006). No Brasil, desde 1995, o Centro Nacional de Tecnologias Limpas do SENAI do Rio Grande do Sul (SENAI-RS, 2003) se dedica à difusão da Produção Mais Limpa. Com base na experiência do SENAI-RS, no modelo ECOPROFIT e no modelo da ONU, foi criada a "Rede Brasileira de Produção Mais Limpa" em 1999 pelo "Conselho Empresarial Brasileiro para o Desenvolvimento Sustentável” em parceria com o SEBRAE e com Universidades que criaram núcleos de Produção Mais Limpa em dezenove Estados do Brasil (REDE BRASILEIRA DE PRODUÇÃO MAIS LIMPA, 2004). Esta rede que completou uma década de atuação no Brasil implementou a Produção Mais Limpa em mais de 300 empresas, proporcionando melhorias no desempenho ambiental e ganhos econômicos.

No Estado de São Paulo, o Centro de Produção Mais Limpa do SENAI-SP é apoiado pela Plataforma de Produção Mais Limpa da Suíça e realiza avaliações para a implementação de Produção Mais Limpa e treinamentos. A Plataforma de Produção Mais Limpa da Suíça provê suporte a treze países em desenvolvimento para acessar tecnologias e metodologias suíças (CPPS, 2006). Por fim, a CETESB mantém um setor de Produção Mais Limpa desde 1996, para publicar documentos técnicos e casos de sucesso, realizar treinamentos e participar em Câmaras Ambientais (CETESB, 2006).

\section{Modelagem do estudo de caso}

Para sintetizar as constatações do estudo de caso sobre o Programa de Produção Mais Limpa da Multinacional Inovadora, será apresentada, a seguir, uma modelagem, de acordo com a metodologia EKD (Enterprise Knowledge Development). Modelar significa descrever um conjunto de fenômenos abstratos ou concretos de modo estruturado. Para isso, a metodologia EKD (Enterprise Knowledge Development) se presta a documentar e analisar os fatores que compõem a organização. Trata-se de uma metodologia que visa apoiar tanto os esforços de mudança organizacional, como a elaboração de sistemas de informação que efetivamente apóiem o desenvolvimento da organização. Para esta pesquisa, a modelagem será subdividida nos seguintes modelos: Objetivos; Regras de Negócio; Processos de Negócio; Atores e Recursos; e de Conceitos. (Bubenko et al., 2001).

\subsection{Modelo de objetivos}

O Modelo de Objetivos apresenta a interdependência entre os objetivos do Programa de Produção Mais Limpa da Multinacional Inovadora, contextualizados em relação às oportunidades que os apóiam e os pontos fracos que os impedem.

O objetivo principal do programa é melhorar a ecoeficiência da empresa, o que implica na obtenção simultânea de ganhos econômicos e da melhoria da sustentabilidade ambiental. Por sua vez, o objetivo de sustentabilidade ambiental pode ser atingido de três modos alternativos: pela redução de poluentes, ou pela utilização mais eficiente de energia, ou pela redução de gases causadores do efeito estufa.

Antes de 2001 (Figura 1), o objetivo de melhorar a ecoeficiência foi favorecido por quatro oportunidades:

a) A cultura inovadora da empresa, na qual as equipes de manufatura e de laboratório acataram o desafio de buscar melhorias nos processos e nos produtos para tornálos mais adequados ao meio ambiente;

b) O fato do fundador do programa ser um funcionário com doutorado em Engenharia Sanitária o qualificou com a reputação necessária para que a alta administração da Multinacional Inovadora aceitasse a idéia de instituir um programa de Produção Mais Limpa em 


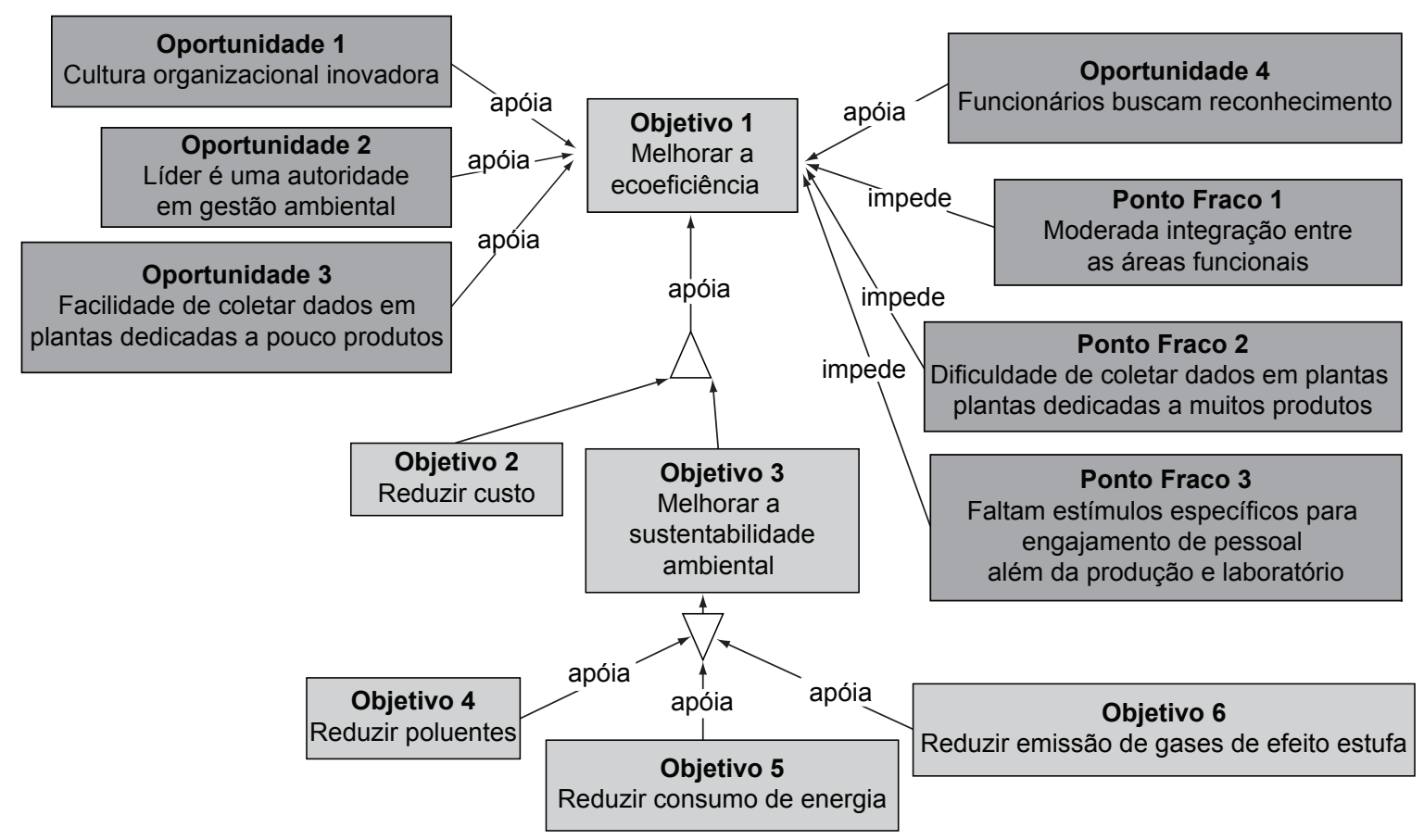

Figura 1. Modelo de Objetivos do Programa de Produção Mais Limpa na Multinacional Inovadora de 1975 a 2001 (Figura dos autores).

uma época em que tanto as empresas como os governos ainda enfatizavam o controle da poluição;

c) Nos EUA, onde o programa foi iniciado, o grande mercado justificava plantas fabris dedicadas a poucos produtos, diminuindo a complexidade de manufatura; e

d) Por fim, o Programa de Produção Mais Limpa em caráter voluntário só gerou resultados, porque os funcionários, nos EUA, se satisfaziam com o reconhecimento público da alta gerência durante os eventos de celebração para os projetos reconhecidos pelo programa.

Por outro lado, antes de 2001 (Figura 1), a subsidiária brasileira se confrontava com os seguintes pontos fracos:

a) A integração entre as diferentes áreas funcionais não era suficientemente forte;

b) A menor demanda do mercado brasileiro obriga as fábricas a produzirem uma maior variedade de produtos para justificar os investimentos, aumentando a complexidade da manufatura e dificultando o trabalho de coleta de dados de desempenho ambiental, o que impedia que a subsidiária brasileira concluísse projetos de Produção Mais Limpa reconhecidos corporativamente; e

c) Além disso, apenas as áreas de manufatura e laboratório se motivavam a participar do programa de Produção Mais Limpa.

Depois de 2001, os objetivos do Programa de Produção Mais Limpa foram favorecidos pelo efeito sinérgico vindo da iniciativa corporativa para se instituir uma cultura organizacional para projetos, por meio de uma estrutura organizacional matricial e de uma metodologia de gestão de projetos com sistemática coleta e validação de dados (Figura 2).

Com isso, os gerentes de projeto tiveram maior autonomia para obter redução de poluição em oportunidades anteriormente intocadas por se encontrarem na interface entre diferentes áreas funcionais, não sendo parte da responsabilidade explícita de nenhuma instância de gestão na empresa. Além disso, a metodologia de gestão de projetos utilizada define uma abordagem sistemática para a coleta e validação da confiabilidade dos dados, o que cumpre com a exigência do programa corporativo de Produção Mais Limpa de se demonstrar quantitativamente os resultados da redução de poluição.

Outra mudança no contexto do programa de Produção Mais Limpa é que, além das adesões voluntárias, foram definidas metas de reduções de poluição para cada manufatura, de modo a se criar um fator motivacional adicional para que as equipes realizem projetos de Produção Mais Limpa.

Por fim, o programa de Produção Mais Limpa criou categorias adicionais para reconhecimento especial de projetos de Produção Mais Limpa realizados por outras áreas funcionais, além da manufatura e do laboratório, como o departamento de logística e o de embalagens. Para estimular a inovação e favorecer uma abordagem mais ampla de sustentabilidade ambiental, também foram criadas categorias de reconhecimento respectiva- 


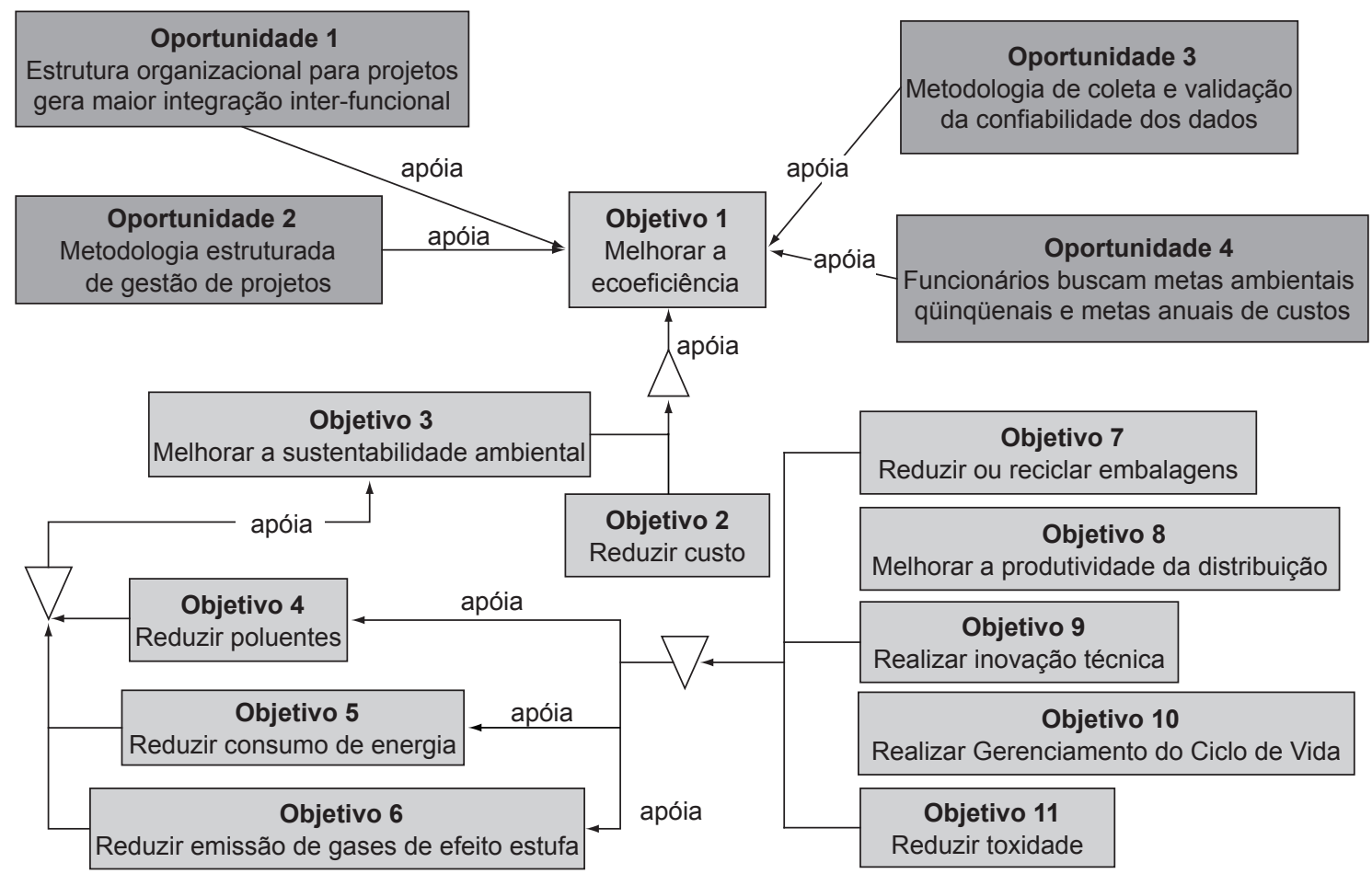

Figura 2. Modelo de Objetivos do Programa de Produção Mais Limpa na Multinacional Inovadora depois de 2002 (Figura dos autores).

mente para significativas inovações tecnológicas e para a redução da toxidade dos produtos ou para a utilização da metodologia de "Gestão do Ciclo de Vida", a qual avalia o impacto ambiental de um produto desde as suas matérias-primas até o seu descarte.

\subsection{Modelo de regras de negócio}

O objetivo de ecoeficiência do Programa de Produção Mais Limpa é favorecido por um conjunto de regras de negócio (Figura 3). Esse objetivo é diretamente apoiado por duas regras: a primeira define que os funcionários da empresa, sobretudo da área de manufatura, são avaliados de acordo com o cumprimento de metas anuais de redução de custo e de metas qüinqüenais de redução de poluição. Já a segunda regra estipula que o reconhecimento oficial pelo programa corporativo de Produção Mais Limpa ocorre para o projeto que atingir os limites mínimos de ganho financeiro e de redução de poluição.

Por outro lado, foram observadas regras indiretas ao programa, que, no entanto, aumentaram a capacidade organizacional para, de fato, se conduzir projetos de Produção Mais Limpa. Trata-se das regras utilizadas para se instituir a estrutura organizacional para a metodologia Seis Sigma de gestão de projetos (Pande et al., 2001):

a) Definição de que a melhoria do desempenho nos processos de negócio deve ser realizada por meio de uma estrutura organizacional matricial por projetos; b) A introdução e difusão da metodologia Seis Sigma para a gestão de projetos deve ser liderada por gerentes de projetos e por treinadores internos da empresa capacitados;

c) A utilização da metodologia de gestão de projetos é cobrada, pela avaliação de cada funcionário quanto ao seu desempenho em liderar projetos utilizando-se do Seis Sigma; e

d) A difusão de projetos de Produção Mais Limpa é favorecida pela replicação de projetos de uma área para outra da empresa. Para isso, o diretor de projetos cria mecanismos para reconhecer o esforço na replicação de projetos.

Por fim, o objetivo de se melhorar a sustentabilidade ambiental da empresa é apoiado pela regra que define que os projetos de Produção Mais Limpa reconhecidos pelo programa devem comprovar a redução de poluição com dados quantitativos. A isto se alinha a regra de projetos Seis Sigma que define a obrigatoriedade de só se utilizar dados com confiabilidade validada.

\subsection{Modelo de Processos de Negócio}

Os objetivos de ecoeficiência da Multinacional Inovadora são realizados pelo processo de negócio para a condução do Programa de Produção Mais Limpa (Figura 4), que obtém redução de poluentes e redução de cus- 


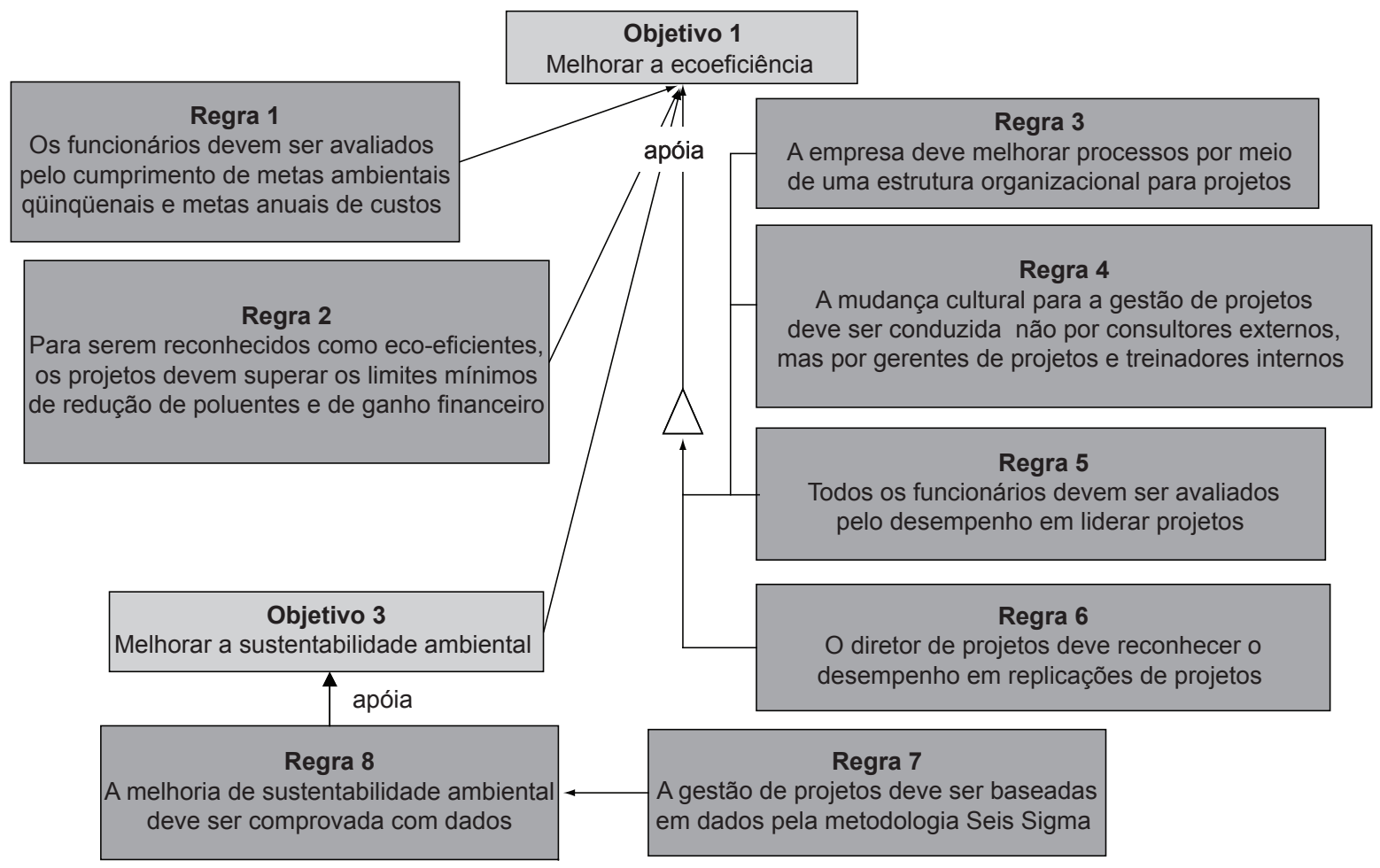

Figura 3. Modelo de Regras de Negócio do Programa de Produção Mais Limpa na Multinacional Inovadora (Figura dos autores).

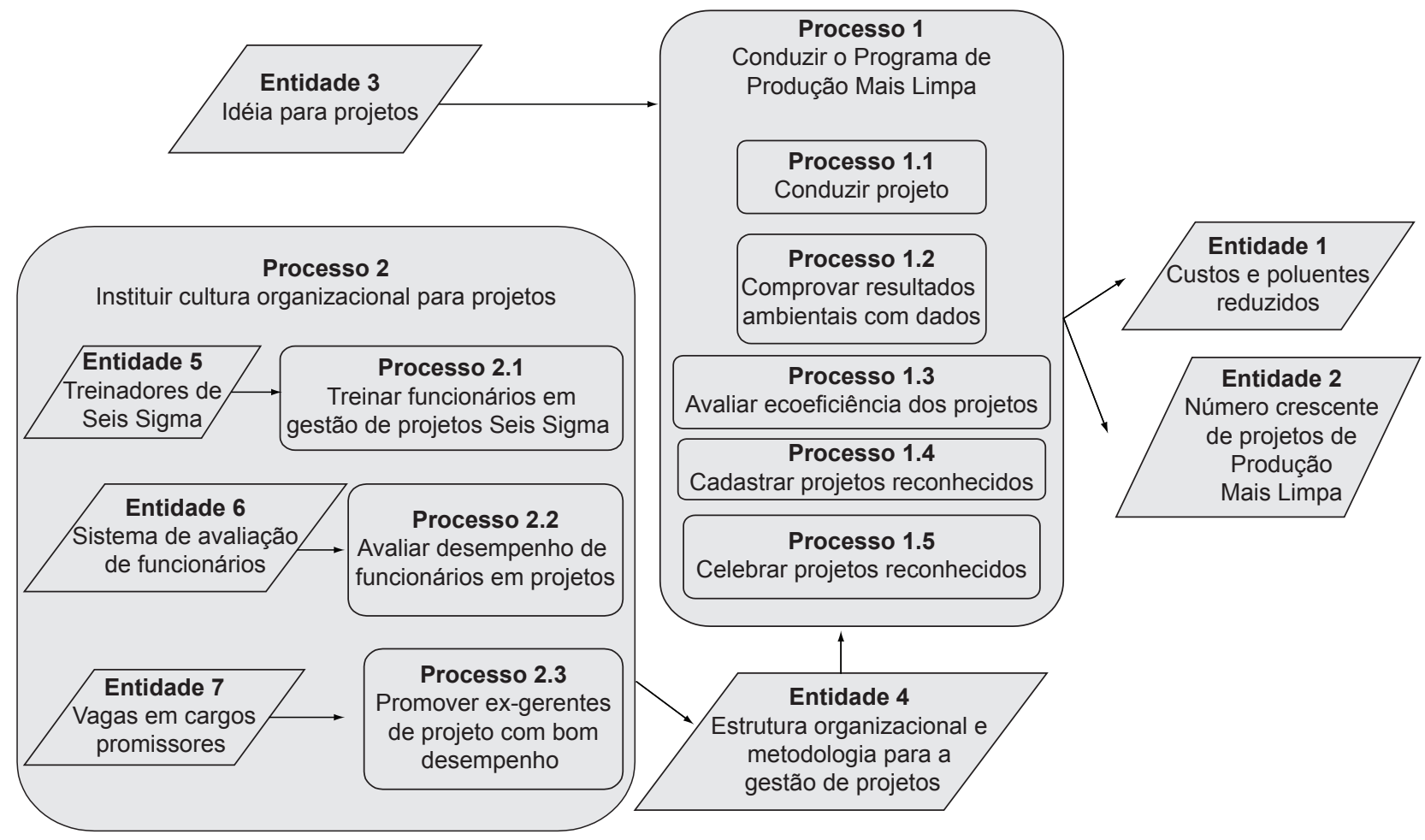

Figura 4. Modelo de Processos de Negócio do Programa de Produção Mais Limpa na Multinacional Inovadora (Figura dos autores). 
tos ao transformar as idéias de novos projetos, por meio das atividades de gestão de projetos e da comprovação quantitativa dos resultados ambientais que, em seguida, são avaliados por um comitê corporativo, cadastrados no banco de dados de projetos reconhecidos e celebrados oficialmente pela alta gestão da subsidiária.

A partir de 2001, o programa de Produção Mais Limpa teve maior difusão, graças à maior capacitação dos funcionários para a gestão de projetos. Portanto, um processo de negócio enfocado na gestão de projetos catalisou o processo de negócio primário de gestão do Programa de Produção Mais Limpa propriamente dito.

Deste modo, o processo para se instituir uma cultura organizacional para projetos disponibilizou uma estrutura organizacional e uma metodologia de gestão de projetos, por meio das atividades de se capacitar os funcionários da empresa na metodologia Seis Sigma, cobrar a utilização da metodologia e a obtenção de resultados nas avaliações dos funcionários e promover os gerentes de projeto com bom desempenho na utilização da metodologia.

\subsection{Modelo de Atores e Recursos}

Os processos de negócio que geram os resultados ambientais e econômicos do programa de Produção Mais Limpa são conduzidos pelos atores que utilizam os recur- sos, conforme o Modelo de Atores e Recursos (Figura 5), no qual os atores são categorizados em Papéis (para pessoas físicas), Unidades Organizacionais (para os grupos de pessoas ou departamentos internos) e Organizações Externas.

Na década de 70, o criador do programa de Produção Mais Limpa instituiu uma nova unidade organizacional na Multinacional Inovadora para integrar representantes dos departamentos mais envolvidos com questões ambientais. Trata-se do comitê corporativo responsável pelo programa de Produção Mais Limpa e que define os critérios de reconhecimento e avalia os projetos que se candidatam ao programa.

Os projetos reconhecidos pelo comitê corporativo são inscritos num evento de reconhecimento, organizado pelo Departamento de Meio Ambiente de cada subsidiária, no qual o presidente da subsidiária entrega troféus de reconhecimento aos integrantes dos projetos reconhecidos. Para isso, o programa corporativo de Produção Mais Limpa recomenda ao presidente e ao Departamento de Meio Ambiente da subsidiária um roteiro de como conduzir estes eventos de reconhecimento. Tais eventos costumam ser bastante simples, com as equipes de projeto recebendo oficialmente os parabéns do presidente da subsidiária na presença dos respectivos chefes, além de uma

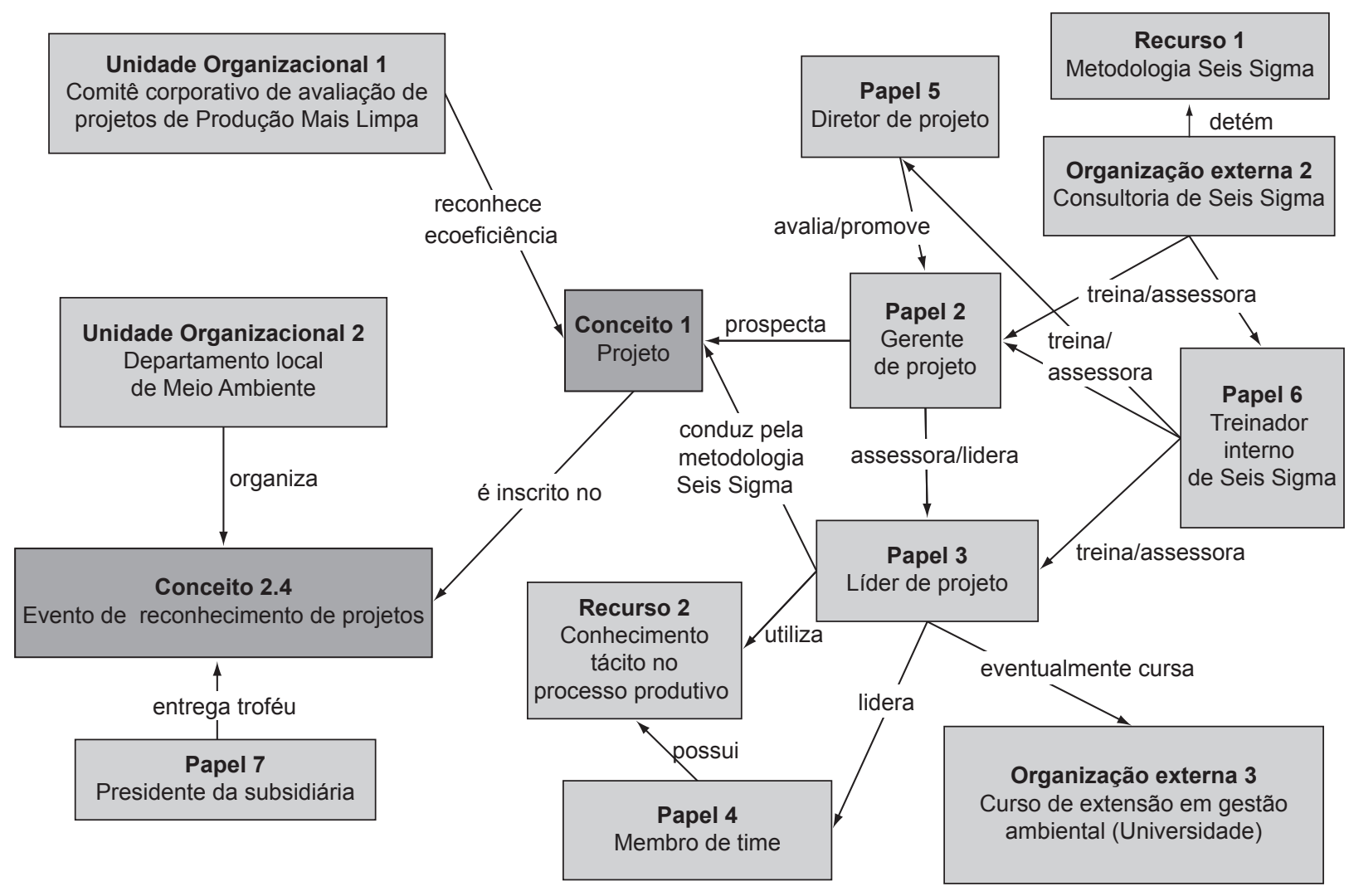

Figura 5. Modelo de Atores e Recursos do Programa de Produção Mais Limpa na Multinacional Inovadora (Figura dos autores). 
veiculação do evento nos meios de comunicação internos da empresa. Esta maior exposição do funcionário contribui para o desenvolvimento da sua carreira, porém não de forma direta, mas de modo incremental ao consolidar a sua reputação profissional.

A maioria dos projetos de Produção Mais Limpa na Multinacional Inovadora é conduzida por um líder de projetos, de acordo com a metodologia Seis Sigma, o qual foi capacitado pelo treinador interno de Seis Sigma e é assessorado e liderado por um gerente de projeto. Por sua vez, o líder de projetos lidera os membros de equipe, que são funcionários especialistas nas atividades operacionais e no conhecimento tácito sobre o processo produtivo. Deste modo, o líder de projetos utiliza o conhecimento tácito dos membros de equipe, de acordo com a estrutura de análise da metodologia Seis Sigma, tanto para diagnosticar as causas da poluição e desperdícios, quanto para definir soluções e novos procedimentos comprovados e estáveis.

Eventualmente, os líderes de projeto tomam a iniciativa de iniciar um projeto de Produção Mais Limpa, a partir dos conhecimentos adquiridos em um curso de extensão em Gestão Ambiental na universidade próxima da subsidiária brasileira.

O gerente de projeto se motiva a liderar e assessorar vários líderes de projeto, pois a sua carreira depende de como o diretor de projetos avalia o seu desempenho durante os poucos anos de duração deste cargo de gerente de projeto. De fato, só são admitidos no cargo de gerente de projeto funcionários com elevado potencial para assumir a liderança da empresa por já terem demonstrado previamente terem liderança e um histórico consistente e convincente de geração de resultados. O cargo de gerente de projetos oferece uma experiência adicional mais intensa para o funcionário demonstrar ser capaz de causar mudanças inovadoras e de elevada contribuição para a competitividade da empresa, de modo a aumentar as evidências do mérito do funcionário para assumir postos de maior responsabilidade em sua carreira após ter concluído o período do cargo de gerente de projetos.

Os primeiros gerentes de projetos, diretores de projetos e treinadores internos de Seis Sigma receberam os conhecimentos formais sobre a metodologia Seis Sigma, por meio de uma consultoria externa de Seis Sigma. Uma vez que se acumulou experiência interna no uso da metodologia e foram formados treinadores internos na corporação, os próprios especialistas internos se responsabilizaram em continuar a difusão e manutenção do conhecimento sobre a metodologia Seis Sigma na empresa.

\subsection{Modelo de Conceitos}

O Modelo de Conceitos define o significado dos termos principais utilizados nos modelos anteriores.

O termo "Programa de Produção Mais Limpa" é definido pelos componentes do programa (Figura 6) na Multinacional Inovadora: um Comitê de Avaliação de Projetos, um conjunto de Critérios para Reconhecimento de Projetos, além de um Banco de Dados mundial para cadastrar os projetos reconhecidos e das recomendações para que as subsidiárias realizem um Evento de Reconhecimento para os projetos selecionados.

Já o termo "Estrutura Organizacional Matricial para Projetos Seis Sigma" é composto por quatro cargos (Figura 7):

a) O diretor de projetos, denominado pela terminologia Seis Sigma como "Mestre Faixa Preta";

b) O cargo temporário de gerente de projeto, ou Faixa Preta, que aloca apenas funcionários com potencial para assumir futuramente parte da alta gestão da empresa;

c) Já o líder de projeto é o Faixa Verde, que é um funcionário da estrutura funcional da empresa treinado para conduzir projetos, de acordo com a metodologia Seis Sigma; e

d) Por fim, o treinador de Seis Sigma difunde e mantém o conhecimento de Seis Sigma na empresa.

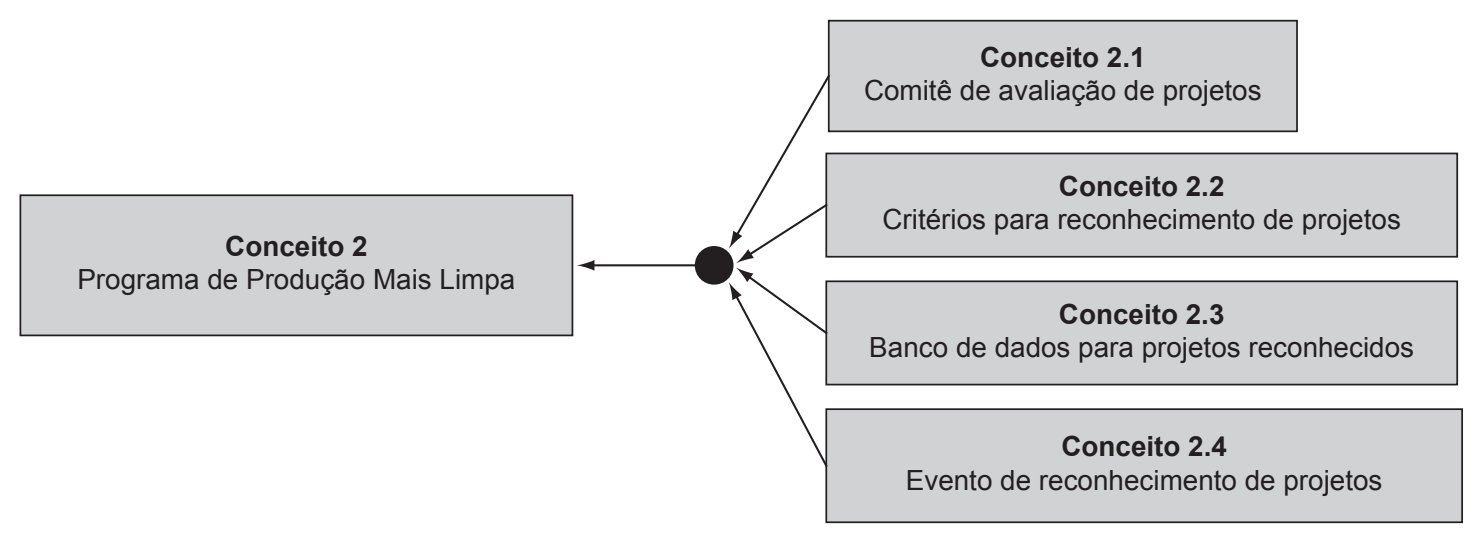

Figura 6. Modelo de Conceitos do Programa de Produção Mais Limpa na Multinacional Inovadora (Figura dos autores). 
Por fim, para os projetos analisados na Multinacional Inovadora, o termo "Metodologia Seis Sigma" segue a estrutura lógica de divisão de projetos em fases de: definição do projeto, mensuração das variáveis dependentes, análise das causas destas variáveis, melhoria e controle do processo de negócio (DMAIC). A Figura 8 resume as ferramentas que são utilizadas em cada fase de um projeto Seis Sigma para a melhoria de processos de negócio.

\section{Considerações finais}

Este artigo buscou contribuir para que as redes responsáveis pela difusão da Produção Mais Limpa nas ma- nufaturas dêem um passo adiante na compreensão dos condicionantes organizacionais para aumentar significativamente seu desempenho na difusão de metodologias ambientalmente sustentáveis.

Partindo da teoria de organização em rede para a difusão de inovações, o artigo se propôs a observar e explicar o motivo pelo qual uma organização em rede de uma empresa multinacional conseguiu triplicar seu desempenho ambiental (medido em toneladas de poluição prevenida) e multiplicar em oito vezes o número de projetos de Produção Mais Limpa concluídos com sucesso.

Finalmente, o artigo se propôs a sistematizar as constatações deste estudo de caso, por meio de uma modela-

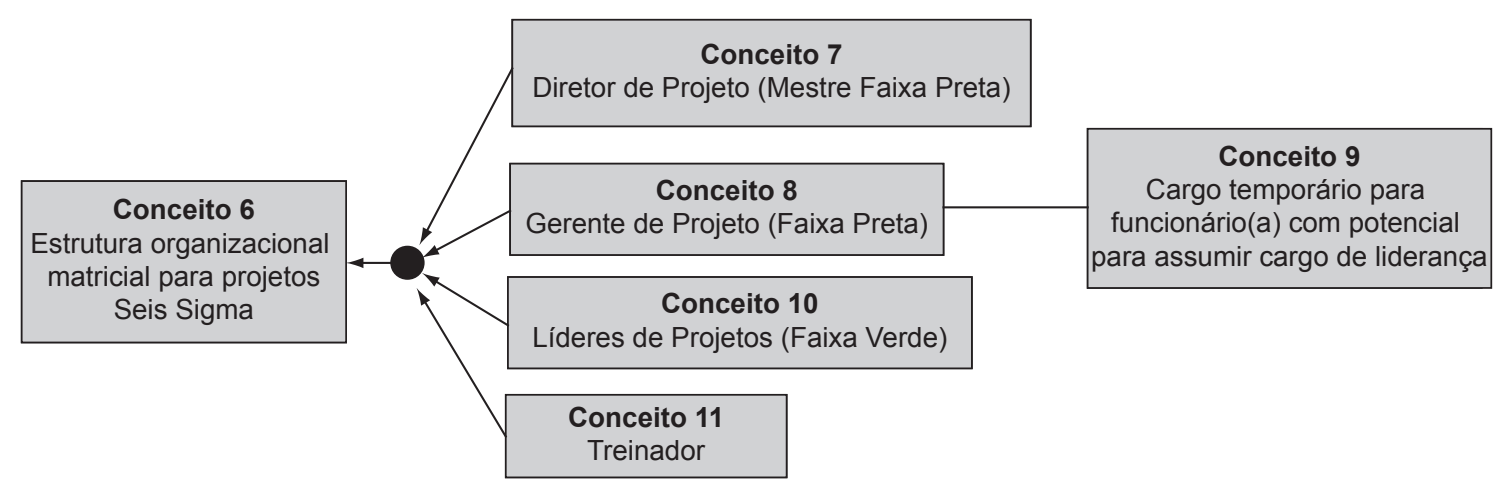

Figura 7. Modelo de Conceitos da Estrutura Organizacional Seis Sigma na Multinacional Inovadora (Figura dos autores).

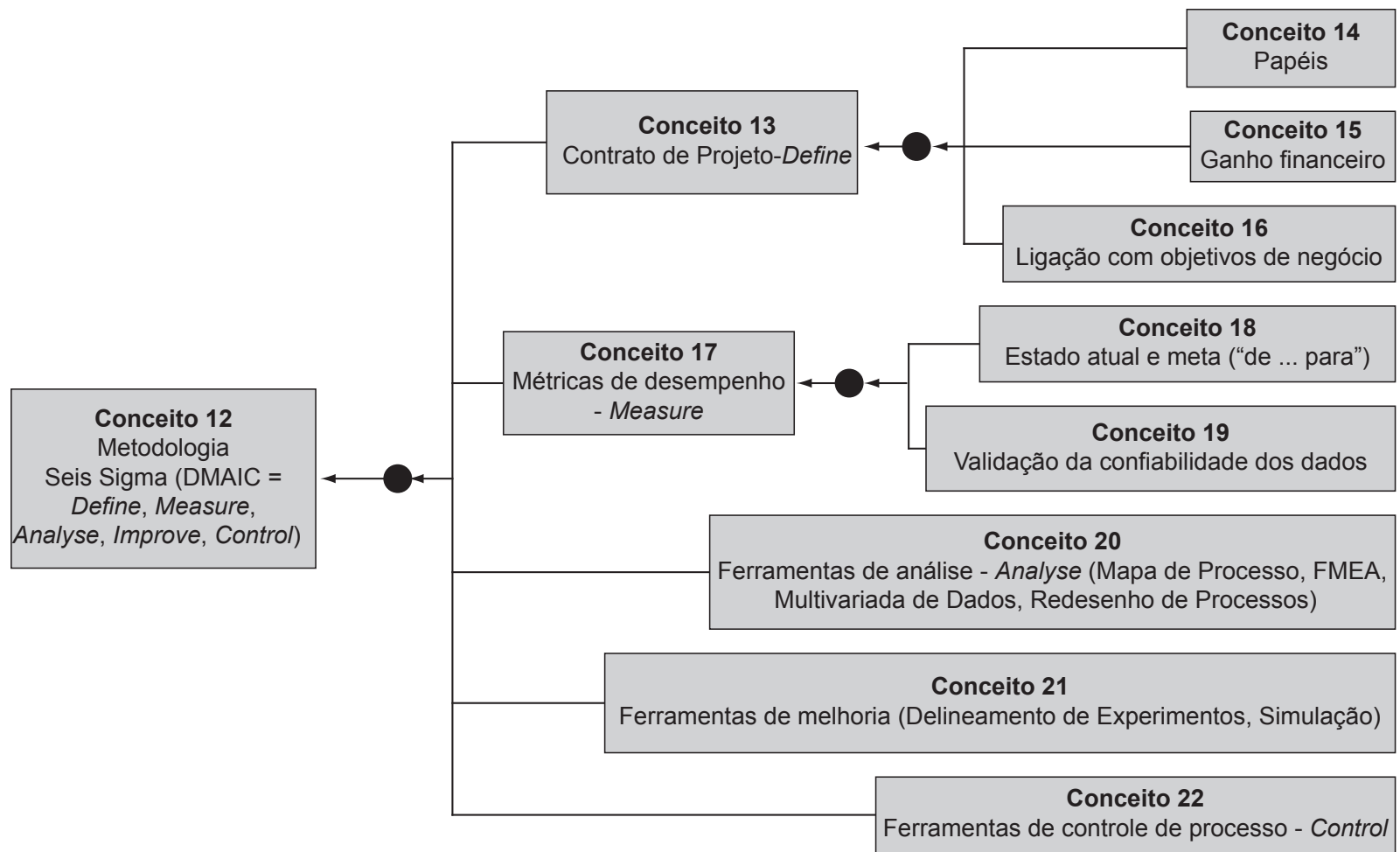

Figura 8. Modelo de Conceitos da metodologia Seis Sigma na Multinacional Inovadora (Figura dos autores). 
gem dos objetivos do Programa de Produção Mais Limpa desta multinacional, assim como de suas regras de negócio e processos de negócio, que dão suporte a tais objetivos e os realizam operacionalmente. Estas diagramações culminam em um modelo de organização em rede, por meio da modelagem dos Atores e Recursos, o qual explicita a composição de competências necessárias para a nova estrutura organizacional, bem como a estrutura de relacionamento entre os atores.

O estudo de caso, por meio de observação participante, análise documental e entrevistas com líderes de projetos de Produção Mais Limpa, facilitou uma detalhada e aprofundada coleta de informações. Por outro lado, a metodologia EKD (Enterprise Knowledge Development) permitiu a clara e concisa compilação destas informações de modo sistematizado, o que deve facilitar eventuais futuros estudos semelhantes em outras organizações em rede de bom desempenho na difusão da Produção Mais Limpa.

Não há dúvida de que o modelo aqui exposto não conta com base empírica suficiente para ser tido como representativo e definitivo para fins prescritivos. Para isso, ainda serão necessários numerosos estudos de caso semelhantes e comprovações estatísticas.

Por outro lado, as descobertas deste artigo devem auxiliar os gestores de redes responsáveis pela difusão da
Produção Mais Limpa a se atentarem mais enfaticamente aos fenômenos estritamente organizacionais como:

a) A utilização de uma metodologia de gestão de projetos de elevada eficácia para o resultado financeiro das manufaturas, a fim de gerar riqueza e, além disso, prevenir a poluição, de modo a superar a barreira de insuficiente motivação de empresários e executivos para apoiar programas de Produção Mais Limpa em suas manufaturas;

b) A adoção de uma estrutura organizacional matricial para projetos atrelada a uma política de gerenciamento de carreiras que reconheça gerentes de projeto com alto desempenho na mudança da cultura organizacional enfocada para a gestão de projetos e melhoria nos processos, de modo a superar a barreira dos funcionários da manufatura exercerem resistência às mudanças propostas pelos programas de Produção Mais Limpa; e

c) E a articulação de uma rede de atores para organizar programas de Produção Mais Limpa, capacitar e liderar empregados funcionais para a gestão de projetos e acolher o conhecimento tácito e prático dos empregados funcionais com experiência nos processos produtivos, de modo a superar a barreira da empresa se limitar a mudanças superficiais de curto prazo, ao criar as capacidades organizacionais que viabilizam a melhoria contínua nos programas de Produção Mais Limpa.

\section{Referências Bibliográficas}

AMATO, J. N. Redes de Cooperação Produtiva e Clusters Regionais. Oportunidades para as pequenas e médias empresas. São Paulo: Atlas, 2000.

BARBIERI, J. C., Gestão ambiental empresarial: conceitos, modelos e instrumentos. São Paulo: Saraiva, 2004.

BARTletT, C.; GHOSHAL, S. Managing Across Borders: The Transnational Solution. Boston: Harvard Business School Press, 1991.

BUBENKO, J.; PERSSON, A.; STIRNA, J.. EKD User Guide, Stockholm: HyperKnowledge, 2001.

CANADIAN CENTRE FOR POLLUTION PREVENTION, Disponível em: <http://www.c2p2online.com/>. Acesso em 9 março 2006.

CETESB, Hierarquia de gerenciamento ambiental de resíduo. Disponível em: < http://www.cetesb.sp.gov.br > Acesso em 8 março de 2006.

CETESB; PNUMA, A produção mais limpa e o consumo sustentável na América Latina e Caribe, São Paulo, 2004.
CLEANER PRODUCTION CENTER AUSTRIA, ÖKOPROFIT®- The idea. Disponível em: <http://www.cpc. at/oeko/oe_WasIst_e.htm> Acesso em 9 março de 2006.

CPPS, Cleaner Production Centers (CPC) Programme Disponível em: < http://www.cpplatform.ch/index1.htm> Acesso em 9 março de 2006.

ECCLES, R.; NOLAN, R. A Framework for the Design of the Emerging Global Organizational Structure. In BRADLEY, Stephan; HAUSMAN, Jerry; NOLAN, Richard (Org.) Globalization, technology, and competition: the fusion of computers and telecommunications in the 1990s. Boston: Harvard Business School Press, 1993.

ENVIROWISE, Minimise Waste, maximise profit. Disponível em: < http://www.envirowise.gov.uk/ > Acesso em 9 março de 2006.

GULATI, R.; GARGIULO, M. Where do interorganizational networks come from? American Journal of Sociology. March 1999: v.104, n.5, 177-231. 1999.

LIPNACK, J.; STAMPS, J. Rede de informações. São Paulo: Makron Books. 1994. 
MELLO, M. C.; NASCIMENTO, L. F. O intangível da produção mais limpa: o mais que ainda é menos, Rio de Janeiro: VIII ENGEMA, 2005.

PANDE, P.; NEUMAN, R.; CAVANAGH, R.. Estratégia Seis Sigma, Rio de Janeiro: Qualitymark, 2001.

PORTER, M. The technological dimension of competitive strategy. 1983 In Burgelman, Robert; Maidique, Modesto. (Org.): Strategic management of technology and innovation. Illinois: Irwin, Homewood, 1988, p. 211-233.

PRAHALAD, C.; HAMEL, G. The core competence of the corporation. Harvard Business Review, v. 68, n. 3, May/Jun. 1990.

PYKA, A.; KÜPPERS, G., Innovation Networks. Edward Elgar Publishing Limited, 2002.

REDE BRASILEIRA DE PRODUÇÃO MAIS LIMPA, Relatório de atividades dos núcleos regionais. Rio de Janeiro, 2004.

SENAI-RS. Implementação de Programas de Produção mais Limpa. Porto Alegre, Centro Nacional de Tecnologias Limpas SENAI-RS/UNIDO/INEP, 2003. 42 p. il.

STEVENS, C. Mapping Innovation The OECD Observer. Number. 207, Aug/Sept, p. 16-19. 1997.
UNEP, Understanding Cleaner Production. Disponível em: < http://www.uneptie.org/pc/cp/understanding_cp/ home.htm> Acesso em 8 março de 2006.

UNIDO, Environmental Management: Success Stories. Disponível em: <http://www.unido.org/doc/4545>. Acesso em 7 março de 2006.

US-ENVIRONMENTAL PROTECTION AGENCY (EPA), Global Warming Disponível em: <http://yosemite.epa. gov/oar/globalwarming.nsf/content/Climate.html> Acesso em 7 março de 2006.

VASCONCELLOS, E.; HEMSLEY, J. Estrutura das Organizações: estruturas tradicionais, estruturas para inovação, estrutura matricial São Paulo: Pioneiro Thomson Learning, 2003.

WILKINSON, I.; YOUNG, L. On cooperating Firms, relations and networks. Journal of Business Research, v. 55, n. 2, p. 123-132. 2002.

WORLD BANK, Implementing Cleaner Production, 1998. Disponível em: <http://www-wds.worldbank.org/ servlet/WDS_IBank_Servlet?pcont=details\&eid=00009 4946_99040905052283> Acesso em 7 março de 2006.

YIN, R. Estudo de Caso - Planejamento e Método. Porto Alegre: Bookman. 2005.

ZARIFIAN, P. Objectif competénce. Paris: Liaisons sociales. 1999.

\title{
ORGANIZATIONAL STRUCTURE FOR CLEANER PRODUCTION DIFFUSION: A CONTRIBUTION OF THE SIX SIGMA METHODOLOGY TO THE CREATION OF INTRA-ORGANIZATIONAL NETWORKS
}

\begin{abstract}
Cleaner Production is a methodology to improve environmental sustainability in manufacturers. Due to its importance for sustainable development, the United Nations and many regional networks have taken on the responsibility to diffuse Cleaner Production methodology. After more than ten years of activity, however, these networks are facing significant and recurrent organizational barriers, which limit their performance. The theories of "networked organizations" for innovation have provided the constructs to conduct a case study about a networked organization inside a multinational company, which operates in numerous manufacturers worldwide. This company has increased its environmental performance three times in terms of prevented pollution and multiplied the number of Cleaner Production projects eight times after implementing a networked organizational structure to increase its capabilities for project management and process improvement. In order to explain the reasons for such increased environmental performance, the paper uses the "Enterprise Knowledge Development" (EKD) methodology to model the objectives, rules and processes of this corporation's Cleaner Production Program, as well as its actor relationship structures, which have enabled innovative capacity to improve in terms of environmental sustainable innovations in manufacturers.
\end{abstract}

Keywords: Cleaner Production, networked organizations, six sigma, EKD Modeling. 
